NBER WORKING PAPER SERIES

\title{
RESERVE REQUIREMENTS ON SOVEREIGN DEBT IN THE PRESENCE OF MORAL HAZARD -- ON DEBTORS OR CREDITORS?
}

\author{
Joshua Aizenman \\ Stephen J. Turnovsky \\ Working Paper 7004 \\ http://www.nber.org/papers/w7004
NATIONAL BUREAU OF ECONOMIC RESEARCH
1050 Massachusetts Avenue
Cambridge, MA 02138
March 1999

The views expressed in this paper are those of the authors and do not reflect those of the National Bureau of Economic Research.

(1) 1999 by Joshua Aizenman and Stephen J. Turnovsky. All rights reserved. Short sections of text, not to exceed two paragraphs, may be quoted without explicit permission provided that full credit, including (-) notice, is given to the source. 
Reserve Requirements on Sovereign Debt in the

Presence of Moral Hazard -- on Debtors or Creditors?

Joshua Aizenman and Stephen J. Turnovsky

NBER Working Paper No. 7004

March 1999

JEL No. F15, F34, F36

\begin{abstract}
This paper characterizes the effects of reserve requirements on financial loans in the presence of moral hazard on the lender side (i.e., the anticipation that the taxpayer will bailout lending banks if large default will occur) and sovereign risk on the borrower side. The impacts of such reserve requirements on the equilibrium degree of default risk and borrowing are analyzed, and their welfare implications for both the borrowing and the lending nations discussed. More generous bailouts financed by the high income block encourage borrowing and increase the probability of default. We show that the introduction of a reserve requirement in either country reduces the risk of default and raises the welfare of both the high income block and the emerging market economies. In these circumstances, the lender's optimal reserve requirement is shown to increase with the expected bailout. Such a policy induces the lender to internalize the expected tax payer cost of the bailout. Thus a more generous bailout that is accompanied by an optimal adjustment in the lender's reserve requirements exactly neutralizes its effects on welfare, leaving welfare in both countries unchanged. Unlike the case of the lender, the effect of the more generous bailout on the borrower's optimal reserve requirement is ambiguous. The imposition of the reserve requirement may also improve the availability of information about the debt exposure of the emerging market economies, which by itself will reduce the optimal lender's reserve requirements, and may prevent "drying up" the market for sovereign debt.
\end{abstract}

Joshua Aizenman

Department of Economics

Dartmouth College

Hanover, NH 03755

and NBER

j.aizenman@dartmouth.edu
Stephen J. Turnovsky

Department of Economics

University of Washington, Seattle

Seattle, WA 98195 
"Accordingly, it might be useful to consider ways in which some added discipline could be imposed on the interbank market. Such discipline, in principle, could be imposed on either debtor or creditor banks. ... Alternatively, the issue of moral hazard in interbank markets could be addressed by charging banks for the existence of the sovereign guarantee, particularly in more vulnerable countries where that guarantee is more likely to be called upon and whose cost might deter some aberrant borrowing. For example, sovereigns could charge an explicit premium, or could impose reserve requirements, earning low or even zero interest rates, on interbank liabilities. Increasing the capital charge on lending banks, instead of on borrowing banks, might also be effective."

Remarks by Chairman Alan Greenspan, May 7, 1998. ${ }^{1}$

\section{Introduction}

The global financial market has been shaken throughout the nineties by a series of major financial crises. In retrospect, the Mexican crisis of 1994-95 was a mild tequila overhang in comparison to the major Asian flu of the late nineties. Attempts to stabilize the global system have led to massive bailouts, the sizes of which seem to increase exponentially. ${ }^{2}$ This experience suggests that the present system cannot survive indefinitely, as the willingness of tax payers in the OECD countries to engage in continuing bailouts is approaching its limits. Growing recognition of this has resulted in a spirited debate among economists, and soul searching among policy makers.

At one end of the spectrum of views, we find believers in the inherent efficiency of private financial intermediation, arguing that the crises are due to global moral hazard generated by quasi public financial institutions and government interventions. The provision of implicit (or explicit) insurance has subsidized private lending at the expense of the tax payers. According to this view, preventing these crises requires alleviating the global moral hazard problem. To accomplish this task may necessitate a scaling down of the role of the IMF and that of other quasi public institutions in orchestrating bailouts.

\footnotetext{
${ }^{1}$ Before the 34th Annual Conference on Bank Structure and Competition of the Federal Reserve Bank of Chicago.

${ }^{2}$ The Mexican bailout required about $\$ 40$ billion. The recent crises in the Far East have triggered commitments of the IMF and the OECD countries to South Korea, Indonesia and Thailand of about \$ 115 billion.
} 
At the other end of the spectrum are economists who argue for stringent capital controls, needed in order to cut international lending to emerging markets. According to this view, large capital flows are destabilizing, and are frequently welfare reducing for both the emerging markets and the OECD countries, potentially benefiting only the speculators.

In between these extremes exists a large array of views. Most share the presumption that we deal with a second-best situation, in which there is no quick fix but welfare can be enhanced by the proper regulatory changes. While prudent borrowing of emerging market economics is beneficial, excessive borrowing may be disadvantageous due to existing distortions. In such an environment, one should either reduce the existing distortions, or induce borrowers and lenders to internalize them. An example of these views is provided by Chairman Alan Greenspan, in his remarks cited above, in which he proposes the imposition of reserve requirements on foreign bank loans as a possible means of imposing discipline on the market.

To put this issue in the broader context, we observe that most mainstream economists agree that approaching free trade in goods and services is beneficial. But such a consensus is lacking when we deal with financial integration. Indeed there is a spirited debate concerning the wisdom of unrestricted capital mobility between the OECD and emerging markets, and various previous studies have identified circumstances in which unlimited capital mobility may be sub-optimal. ${ }^{3}$

The notion of introducing reserve requirements as a means of stabilizing capital flows between advanced and emerging markets is an innovative idea, one that merits serious analysis. The novel aspect of this paper is in applying a public finance framework to evaluate the general macroeconomic impact of reserve requirements in a second-best world, where in the absence of credible pre-commitments, we observe moral hazard on the lender's side, and sovereign risk on the borrower's side. We are particularly concerned with determining how the effects of bailouts interact with the reserve requirements and how the optimal design of reserve requirements is impacted.

\footnotetext{
${ }^{3}$ See, for example, McKinnon (1982), Diaz-Alejandro (1984), Kletzer (1984), Aizenman (1989). For recent contributors, see McKinnon and Pill (1996), Krugman (1988), Rodrik (1998), Agénor and Aizenman (1998), and Caballero and Krishnamurthy (1998).
} 
An important objective of our analysis is to identify the welfare consequence of imposing a country-specific reserve requirement, and to investigate in whose interest these regulations would work. We consider costly financial intermediation between lenders and emerging markets in the presence of sovereign risk. Moral hazard is modeled on the lender side, due to the "Too-Big-to-Fail" doctrine -large defaults of major banks are destabilizing, hence agents expect public bailout for large defaults. ${ }^{4}$ There is uncertainty regarding the default size that would trigger such a bailout, where larger defaults are associated with higher probability of bailout. While debtors may benefit from imposing a reserve requirement on borrowed funds, the presence of moral hazard on the lender side reduces the borrower's incentive to restrict borrowing.

Our results are summarized in a series of propositions that highlight the importance of reserve requirements in determining the welfare effects of a more generous bailout. Specifically, we shall show that a more generous bailout, financed by the high income block, encourages borrowing and increases the probability of default, thereby raising the expected yield to lenders. In the absence of reserve requirements, the associated higher bailout costs have a positive welfare effect on the borrowing country but at the expense of the lending country. The impact on overall world welfare depends upon whether the net benefits of the higher lending exceed the higher monitoring costs, ultimately paid by the borrowers. At the same time we show that the introduction of a reserve requirement in either country reduces the risk of default and raises the welfare of both the high income block and the emerging market economies. In these circumstances, the lender's optimal reserve requirement is shown to increase with the expected bailout. Such a policy induces the lender to internalize the expected tax payer cost of the bailout. Thus a more generous bailout that is accompanied by an optimal adjustment in the lender's reserve requirements exactly neutralizes its effects on welfare, leaving welfare in both countries unchanged. The effect of a more generous bailout on the borrower's optimal reserve requirement is ambiguous as are the welfare effects. We also contrast the optimal choices of reserve requirements in the two cases where the agents act non-cooperatively with the optimum chosen by a global planner,

${ }^{4}$ This doctrine goes back to the nineteenth century, when Bagehot identified circumstances where systemic risk would induce the central bank to act as the lender of last resort. See Hughes and Mester (1993) for a recent empirical evidence on the "Too-Big-to-Fail" doctrine is the U.S. 
thereby enabling us to identify the impact of the externality on the policy choice. Finally, we show that the imposition of the reserve requirement may also improve the availability of information about the debt exposure of the emerging market economies, which by itself will reduce the optimal reserve requirement, and may prevent the drying up of the market for sovereign debt.

The remainder of the paper is structured as follows. Section 2 outlines the model and identifies the supply of debt and introduces reserve requirements. Section 3 discusses the equilibrium borrowing and lending and analyzes the effects of changes in reserve requirements and in more generous bailouts on the equilibrium. Section 4 analyzes the effects of these changes on the respective welfare of lenders and borrowers, and characterizes the optimal reserve requirement from the perspective of the various parties, on the assumption of a non-cooperative environment, in which each regulator designs the optimal regulation from his perspective, taking the other's regulation as given. Section 5 briefly discusses the globally optimal choice of reserve requirements, while Section 6 identifies another rationale for reserve requirements, namely as a mechanism for improving the transparency of borrower's debt exposure. Section 7 concludes.

\section{The model}

Consider a global economy consisting of two blocks, high-income countries and emerging market economies, and assume a two-period planning horizon. Agents in the high-income countries are risk neutral, and their preferences are

$$
V \equiv C_{1}+\frac{C_{2}}{1+\rho}
$$

where $\rho$ is the rate of time discount and coincides with the risk-free interest rate. Agents in the emerging market are also risk neutral, having preferences represented by

$$
V^{*} \equiv C_{1}^{*}+\frac{C_{2}^{*}}{1+\rho^{*}}
$$


where we assume that their rate of time preference, $\rho^{*}>\rho$, reflecting the fact that the real interest rate in the emerging market economy is (substantially) higher than in the high income block. Output in the high-income and the emerging market blocks at time $\mathrm{t}$ is $Y_{t}, Y_{t}^{*}$, respectively, with $Y_{t} \gg Y_{t}^{*}$. The only source of macro uncertainty is the stochastic shock, $\varepsilon$, to second period output in the emerging market block

$$
Y_{2}^{*}=Y^{*}(1+\varepsilon)
$$

where $\varepsilon$ is governed by the probability density function $f(\varepsilon),-\bar{\varepsilon} \leq \varepsilon \leq \bar{\varepsilon}, \bar{\varepsilon} \geq 0$. All private agents are price takers.

\subsection{Borrowing Constraints and Reserve Requirements}

The emerging markets block may borrow internationally, but its borrowing capacity is restricted by the limited enforceability of international contracts. ${ }^{5}$ To simplify the analysis we consider the case where the initial outstanding foreign debt is zero. Suppose that the high income block lends an aggregate amount $B_{1}$ in period 1 to the emerging market block at a contractual interest rate of $r$. We shall assume further that the lending agency is required to maintain a fraction $\theta$ of its loans as reserves that yield a zero real interest rate. Thus, with the reserve requirement, gross lending by the high income block, $B_{1}$, is associated with net lending to the emerging market of

$$
B_{1}^{*} \equiv(1-\theta) B_{1},
$$

as a fraction $\theta B_{1}$ is lend to the central bank. Hence the reserve requirement provides the fiscal authorities with an interest-free loan, leading to second-period income of $\rho \theta B_{1}$.

In period 2, the borrowing country is required to repay its net loan, $B_{1}^{*}$, but because of the stochastic output it may default partially. Let $S_{2}$ denote the debt repayment to foreign creditors in period 2. In the event of default, creditors are assumed to be able to penalize the borrowing country,

${ }^{5}$ See Eaton at. al. (1986), Chapter 6 in Obstfeld and Rogoff (1996) for a review of the literature on sovereign debt, and Bulow and Rogoff (1989) and Helpman (1989) for related models. 
reducing its net output by $\chi Y_{2}^{*}$. The parameter $\chi$ reflects the bargaining power of foreign lenders, indicating that up to a fraction $\chi$ of output can "confiscated" due to the threat of embargoes, etc. ${ }^{6}$ Consequently, the effective ceiling on net resource transfers to creditors is:

$$
S_{2}=\min \left[(1+r) B_{1}^{*}, \chi Y_{2}^{*}\right]
$$

Equation (5) implies that the productivity threshold leading to partial default, $\varepsilon^{*}$, is determined by the condition $(1+r) B_{1}^{*}=\chi Y^{*}\left(1+\varepsilon^{*}\right)$, implying that:

$$
\varepsilon^{*}=\max \left\lfloor\frac{(1+r) B_{1}^{*}}{\chi Y^{*}}-1,-\bar{\varepsilon}\right\rfloor
$$

For realized productivity below $\varepsilon^{*}$, partial default saves the borrower (at the expense of the lender) the difference between the contractual repayment and the actual one. We denote this gap -- the potential bailout -- by $b$

$$
b \equiv(1+r) B_{1}^{*}-\chi Y^{*}(1+\varepsilon)=\chi Y^{*}\left(\varepsilon^{*}-\varepsilon\right)
$$

The international credit market is risk neutral, characterized by competition among banks that are fully informed regarding the debt exposure of the country. Partial default by the emerging markets requires that banks should spend real resources $\mu$ in order to verify the productivity shock and to enforce the repayment according to (5). ${ }^{7}$

Large defaults are potentially destabilizing, leading agents to expect the possibility of public bailouts. There is, however, uncertainty regarding the exact default size leading to the bailout. We

${ }^{6}$ The term $\chi$ captures all the factors that may influence the integration of markets [like openness, trade dependency, the state of the global economy, etc.].

${ }^{7}$ To simplify, we lump these costs together and we ignore the possibility of randomized monitoring [see Towsend (1979) for a model where a debt contract is optimal in the presence of state verification costs]. As was shown by Boyd and Smith (1994), random monitoring adds significant complexity to the financial contract, without generating first order welfare effects [see also Bernanke and Gertler (1989) for a related analysis]. 
summarize the bailout expectations in a reduced form equation, where the bailout probability $\phi$ increases with the default size:

$$
\phi=\phi(b), \text { where } \phi(0)=\phi^{\prime}(0)=0 ; \phi^{\prime}(b)>0 \text { for } b>0
$$

In the event of a bailout, the tax payer would compensate fully the lenders for the revenue shortfall induced by default, $b .{ }^{8}$ Hence, with the bailout, the bank's income on the foreign loan $B_{1}^{*}$ is $b+\chi Y^{*}(1+\varepsilon)$, which equals the contractual repayment, $B_{1}^{*}(1+r)$.

We assume that the partial default decision is centralized, being made and enforced by the policy maker (like the Central Bank or the Treasury), who follows the default rule described by (6). Suppose that the policy maker in the emerging market imposes a borrower's reserve requirement $\theta^{*}$ on borrowed funds. Although the aggregate borrowing of the emerging market block is $B_{1}^{*}=(1-\theta) B_{1}$, only $\left(1-\theta^{*}\right) B_{1}^{*}$ is available to the private sector directly. The remaining borrowed funds, $\theta^{*} B_{1}^{*}$, are set aside in a reserve account that is assumed to yield a zero real interest rate. An agency of the central bank borrows from the foreign banks $B_{1}^{*}=(1-\theta) B_{1}$, and intermediates the foreign loans to domestic borrowers, charging a domestic interest rate $r^{*}$, and imposes the borrower's reserve requirement. This agency collects the interest repayments in states of nature where no external default occur (i.e., when $\left.\varepsilon>\varepsilon^{*}=(1+r) B_{1}^{*} / \chi Y^{*}-1\right)$. In states of partial default, this agency collects the partial default repayment, $\left(1+\varepsilon^{*}\right) \chi Y^{*}$. Any net revenue of this agency is reimbursed to the public in the merging market in a lump-sum fashion. ${ }^{9}$ If there is no default, the loan repayment is financed by the domestic interest rate, $r^{*}$, in accordance with $1+r=\left(1-\theta^{*}\right)\left(1+r^{*}\right)+\theta^{*} \cdot 1$. The borrower's reserve requirement thus induces a wedge between the interest rate, $r^{*}$, facing private agents in the emerging market, and the contractual interest rate, $r$, charged by the lender on sovereign debt, summarized by the relationship:

$$
r^{*}\left(1-\theta^{*}\right)=r
$$

${ }^{8}$ We can extend the analysis to account for partial bailouts, without modifying the key insights. ${ }^{9}$ Alternatively, taxes are imposed if the net revenue is negative. In our example, the imposition of reserve requirements on borrowing implies that the agency gets an interest-free loan, ending up with net revenue. 


\section{Equilibrium Borrowing and Lending}

The intertemporal pattern of consumption is determined by agents who maximize their discounted expected utility. The lender's risk neutrality implies that they offer an elastic supply of credit at an expected yield equal to their time preference rate [see equation (1)]. Hence, the interest rate $r$ is determined by an arbitrage condition, equating the expected yield on foreign debt to the risk free interest rate. The former, given by the right hand side of (10) consists of the following components: (i) the return on the loan in the absence of default; (ii) the return on the loan in the presence of default, which equals the full return on the debt in the event of a bailout and the share of foreign output claimed in the absence of a bailout, all less the enforcement costs; and (iii) the return of the reserve on the loan.

$$
\begin{aligned}
(1+\rho) B_{1} & =(1+r) B_{1}(1-\theta) \int_{\varepsilon^{*}}^{\varepsilon} f(\varepsilon) d \varepsilon+\int_{-\bar{\varepsilon}}^{\varepsilon^{*}}\left\{\phi(1+r) B_{1}(1-\theta)+(1-\phi) \chi Y^{*}(1+\varepsilon)-\mu\right\} f(\varepsilon) d \varepsilon+\theta B_{1} \\
& =(1+r) B_{1}(1-\theta)-\int_{-\varepsilon}^{\varepsilon^{*}}\left\{\left[(1+r) B_{1}(1-\theta)-\chi Y^{*}(1+\varepsilon)\right](1-\phi)+\mu\right\} f(\varepsilon) d \varepsilon+B_{1} \theta
\end{aligned}
$$

Recalling (6) and (7) enables the right hand side of (10) to be written as:

$$
[1+r(1-\theta)] B_{1}-\int_{-\bar{\varepsilon}}^{\varepsilon^{*}}\{b(1-\phi)+\mu\} f(\varepsilon) d \varepsilon
$$

Thus equations (10) and (10') imply that the financial spread is

$$
[r(1-\theta)-\rho] B_{1}=\int_{-\bar{\varepsilon}}^{\varepsilon^{*}}\{b(1-\phi)+\mu\} f(\varepsilon) d \varepsilon
$$

Equation (11) is a fundamental financial equilibrium relationship in the model. The risk premium implied by (11) reflects the presence of default risk; in the absence of default risk, this equilibrium condition implies $r(1-\theta)=\rho$.

Relationships such as (11) have been used to justify the presence of an upward sloping supply

curve of debt, facing developing countries. Beginning with Bardhan (1967), several authors have introduced reduced form relationships of the form $r=r\left(B_{1}\right), r^{\prime}>0$ to reflect foreign asset market 
imperfections into macro models of developing economies; see e.g. Bhandari, Haque, and Turnovsky (1990). Taking the derivatives of (11), (7) and (6), one can show:

$$
\frac{d \ln (1+r)}{d \ln B_{1}}=\frac{1}{\int_{\varepsilon}^{\varepsilon} f(\varepsilon) d \varepsilon-\omega} \frac{1+\rho+\theta r}{1+r}-1
$$

where:

$$
\omega \equiv \frac{d}{d b} \int_{-\bar{\varepsilon}}^{\varepsilon^{*}}(\mu-b \phi) f(\varepsilon) d \varepsilon
$$

Evaluating the expression in (13), we may write $\omega$ in the equivalent form

$$
\omega=\frac{\mu f\left(\varepsilon^{*}\right)}{\chi Y^{*}}-\int_{-\bar{\varepsilon}}^{\varepsilon^{*}} \phi\left(1+\eta_{\phi, b}\right) f(\varepsilon) d \varepsilon
$$

where $\eta_{\phi, b}=d \ln \phi / d \ln b$ is the elasticity of the bailout probability with respect to the bailout size.

The expected repayment of the emerging market on its external debt of $B_{1}^{*}$ is

$$
(1+r) B_{1}^{*} \int_{\varepsilon^{*}}^{\bar{\varepsilon}} f(\varepsilon) d \varepsilon+\int_{-\bar{\varepsilon}}^{\varepsilon^{*}} \chi Y^{*}(1+\varepsilon) f(\varepsilon) d \varepsilon=(1+r) B_{1}^{*}-\int_{-\bar{\varepsilon}}^{\varepsilon^{*}} b f(\varepsilon) d \varepsilon
$$

which, using the equilibrium arbitrage condition (11), can be written

$$
\left\{1+\frac{\rho}{1-\theta}\right\} B_{1}^{*}+\int_{-\varepsilon}^{\varepsilon^{*}}\{\mu-b \phi\} f(\varepsilon) d \varepsilon
$$

From this expression we see that the bailout impacts in two ways on the budget of the borrowing economy. First, there are the expected intermediation costs $\mu \int_{-\varepsilon}^{\varepsilon^{*}} f(\varepsilon) d \varepsilon$, paid directly by the lenders, but passed on to the borrowers through the higher lending rate, $r$. Offsetting this, the bailout subsidizes borrowing by $\int_{-\varepsilon}^{\varepsilon^{*}} b \phi f(\varepsilon) d \varepsilon$. This is also the expected net transfer from the tax payers in the high income block to the banks (and indirectly to the borrower country).

Returning to (12) and (13), we see that $\omega$ represents the marginal impact of a larger bailout on the net expected bailout costs to the borrowing country. Combining these two equations we see that the familiar assumption, $d r / d B_{1}>0$, holds if and only if: 


$$
0<\int_{\varepsilon^{*}}^{\bar{\varepsilon}} f(\varepsilon) d \varepsilon-\omega<\frac{1+\rho+\theta r}{1+r}
$$

which under plausible conditions is likely to be met, and a condition that henceforth is assumed. ${ }^{10}$

The final component of the equilibrium in the world economy is the interest rate parity condition in the borrowing country. Being a price-taker, the agent in that economy views the interest rate and the default threshold, $\varepsilon^{*}$, as exogenously given, determined by the corresponding aggregate variables. The agent in the emerging market determines his borrowing by maximizing his expected utility, where from his point of view the interest rate is $r^{*}$. Given risk neutrality, the first order condition characterizing optimal borrowing by the agent in the borrowing country is ${ }^{11}$

$$
1+\rho^{*}=\left(1+r^{*}\right) \int_{\varepsilon^{*}}^{\varepsilon} f(\varepsilon) d \varepsilon
$$

The equilibrium interest rate in the borrowing country thus exceeds the rate of time preference there by an amount that depends upon the probability of default.

${ }^{10}$ The critical default level, $\varepsilon^{*}$, increases with the level of external debt. For a sufficiently low level of such debt, $\varepsilon^{*}=-\bar{\varepsilon}$, and (12) and (13') imply that the critical condition (14) for $d r / d B_{1}>0$ reduces to $\mu f(-\bar{\varepsilon}) / \chi Y^{*}<1$, a condition that is satisfied for a low enough but positive enforcement cost, $\mu$. If $\mu f(-\bar{\varepsilon}) / \chi Y^{*}>1$, the supply of credit is backward bending at interest rates marginally above the risk-free rate. In these circumstances it would be in the interest of the borrower's central bank to prohibit borrowing, rendering the problem being analyzed in this paper trivial. Consequently, we assume $\mu f(-\bar{\varepsilon}) / \chi Y^{*}<1$, implying that the supply of credit is upward sloping at relatively low interest rates. In general, the external debt-borrowing rate relationship may include a backward bending portion, as will be the case for high enough interest rate and external debt. In these circumstance it would be in the interest of the borrower's central bank to apply policies that would prevent reaching the backward bending portion [a point on the backward bending portion of the supply of credit entails lower welfare than the point where the external borrowing is maximized, see Aizenman (1989) for further discussion of related issues]. Due to these considerations, we assume that we operate in the range where (14) is satisfied.

${ }^{11}$ The expected welfare of a risk-neutral representative agent in the merging market block is

$$
V_{i}^{*} \equiv Y_{1 i}^{*}+B_{1, i}^{*}-T_{1 i}^{*}+\frac{1}{1+\rho^{*}}\left[\int_{\varepsilon^{*}}^{\dot{\varepsilon}}\left[Y_{i}^{*}(1+\varepsilon)-B_{1, i}^{*}\left(1+r^{*}\right)-T_{2, i}^{*}\right] f(\varepsilon) d \varepsilon+\int_{-\varepsilon}^{\varepsilon^{*}}\left[(1-\chi) Y_{i}^{*}(1+\varepsilon)-T_{2 i}^{*}\right] f(\varepsilon) d \varepsilon\right]
$$

where $B_{1 i}^{*}$ the foreign borrowing by agent $\mathrm{i}$, and $T_{1 i}^{*}$ and $T_{2, i}^{*}$ denote lump sum taxes. the agent determines his borrowing by maximizing his expected utility with respect to $B_{1 i}^{*}$. The agent is price taker -- he views the interest rate and the default threshold $\varepsilon^{*}$ as exogenously given, determined by the corresponding aggregate variables. The resultant first-order condition is (15). 


\subsection{Effects of Reserve Requirements}

The equilibrium in the world economy is summarized by the six relationships, (11), (6), (7), (15), (4), and (9), repeated here for convenience:

$$
\begin{aligned}
& {[r(1-\theta)-\rho] B_{1}=\int_{-\bar{\varepsilon}}^{\varepsilon^{*}}\{b(1-\phi)+\mu\} f(\varepsilon) d \varepsilon} \\
& \chi Y^{*}\left(1+\varepsilon^{*}\right)=(1+r) B_{1}(1-\theta) \\
& \left.b=\chi Y^{*}\left(\varepsilon^{*}-\varepsilon\right) \quad \text { (for } \varepsilon<\varepsilon^{*}\right) \\
& \left(1+r^{*}\right) \int_{\varepsilon^{*}}^{\varepsilon} f(\varepsilon) d \varepsilon=1+\rho^{*} \\
& B_{1}^{*} \equiv(1-\theta) B_{1}, \\
& r^{*}\left(1-\theta^{*}\right)=r
\end{aligned}
$$

These relationships determine the equilibrium solutions for gross lending, $B_{1}$, net lending, $B_{1}^{*}$, the international contractual lending rate, $r$, the interest rate in the emerging market, $r^{*}$, the threshold breakeven productivity shock (probability of default), $\varepsilon^{*}$, and the (stochastic) bailout, $b$, in terms of the lending and borrowing reserve requirements, $\theta, \theta^{*}$, and other aspects of the probability distribution characterizing the bailout.

Substituting: (i) for $r$ from (16b), for $B_{1}$ from (16e), and for $b$ from (16c) into the interest arbitrage relationship for the lending country, (16a); and (ii) for $r$ from (16b) and for $r^{*}$ from (16f) into the interest arbitrage relationship for the borrowing country, (16d), enables us to reduce the equilibrium to the following pair of relationships:

$$
\begin{gathered}
\left(1+\varepsilon^{*}\right) \chi Y^{*}-\left[1+\frac{\rho}{1-\theta}\right] B_{1}^{*}-\int_{-\bar{\varepsilon}}^{\varepsilon^{*}}\left\{\chi Y^{*}\left(\varepsilon^{*}-\varepsilon\right)(1-\phi)+\mu\right\} f(\varepsilon) d \varepsilon=0 \\
{\left[\left(1+\varepsilon^{*}\right) \chi Y^{*}-\theta^{*} B_{1}^{*}\right] \int_{\varepsilon}^{\varepsilon} f(\varepsilon) d \varepsilon-\left(1-\theta^{*}\right)\left(1+\rho^{*}\right) B_{1}^{*}=0}
\end{gathered}
$$


These conditions describe equilibrium in (i) the world lending market, and (ii) the internal financial market in the emerging block, the solution to which jointly determines the values of $\left(\varepsilon^{*}, B_{1}^{*}\right)$ for a given pair of reserve requirements, $\left(\theta, \theta^{*}\right)$ and the characteristics of the bailout.

From these relationships we see that the effects of changes of reserve requirements on $\left(\varepsilon^{*}, B_{1}^{*}\right)$ can be summarized in the form

$$
\begin{aligned}
& \frac{\partial \varepsilon^{*}}{\partial \theta}=\frac{B_{1}^{*} \rho(1+r)}{\Delta(1-\theta)^{2}} \int_{\varepsilon^{*}}^{\bar{\varepsilon}} f(\varepsilon) d \varepsilon<0 \\
& \frac{\partial B_{1}^{*}}{\partial \theta}=\frac{\chi Y^{*}}{\Delta} \frac{B_{1}^{*} \rho}{(1-\theta)^{2}} \Gamma<0
\end{aligned}
$$

where $\quad \Gamma \equiv \int_{\varepsilon^{*}}^{\bar{\varepsilon}} f(\varepsilon) d \varepsilon-\left(1+\varepsilon^{*}\right)\left(1-\frac{\theta^{*}}{1+r}\right) f\left(\varepsilon^{*}\right)$

$$
\begin{aligned}
& \frac{\partial \varepsilon^{*}}{\partial \theta^{*}}=\frac{B_{1}^{*} r^{*}}{\Delta}\left(1+\frac{\rho}{1-\theta}\right) \int_{\varepsilon^{*}}^{\bar{\varepsilon}} f(\varepsilon) d \varepsilon<0 \\
& \frac{\partial B_{1}^{*}}{\partial \theta^{*}}=\frac{B_{1}^{*} r^{*}}{\Delta} \chi Y^{*}\left[\int_{\varepsilon^{*}}^{\bar{\varepsilon}} f(\varepsilon) d \varepsilon-\omega\right] \int_{\varepsilon^{*}}^{\bar{\varepsilon}} f(\varepsilon) d \varepsilon<0
\end{aligned}
$$

where $\Delta \equiv \chi Y^{*}\left[-\left(1+\frac{\rho}{1-\theta}\right) \Gamma+\left(\int_{\varepsilon^{*}}^{\bar{\varepsilon}} f(\varepsilon) d \varepsilon-\omega\right)(1+r) \int_{\varepsilon^{*}}^{\bar{\varepsilon}} f(\varepsilon) d \varepsilon\right]$

In imposing the above signs, we are making two plausible assumptions -- $\Delta<0$ and $\Gamma>0$-the rationale for which we now discuss. First, both $(18 \mathrm{~b})$ and $\Delta$ contain the expression $\Gamma$. To interpret this quantity, consider the equilibrium condition (16d), the left hand side of which can be interpreted as the mean borrowing costs (inclusive of debt repayment), say $c$, in the emerging block economy [i.e., $\left.c \equiv\left(1+r^{*}\right) \int_{\varepsilon^{*}}^{\bar{\varepsilon}} f(\varepsilon) d \varepsilon\right]$. It is readily established that the partial effect of a higher threshold break-even productivity shock, $\varepsilon^{*}$, and therefore of a higher probability of default, on the mean cost of funds in the borrowing economy is given by $\left(\partial c / \partial \varepsilon^{*}\right)_{B_{1}^{*} \text { const }}=(1+r) \Gamma /\left(1+\varepsilon^{*}\right)\left(1-\theta^{*}\right)$. On the one hand higher $\varepsilon^{*}$ raises the contractual lending rate, thereby raising $r^{*}$, but it also raises the probability of default and eventual bailout, thereby lowering borrowing costs . It is plausible to assume that the former effect dominates, so that $\Gamma>0$, implying that higher default risk is associated with higher borrowing costs. 
Second, consider the term $l \equiv 1+r(1-\theta)-\int_{-\varepsilon}^{\varepsilon^{*}}\left[(b(1-\phi)+\mu) / B_{1}\right] f(\varepsilon) d \varepsilon$, obtained from (16a).

This reflects the mean return on the loan to the lending country and consists of the loan rate net of the reserve requirement less the net costs of partial default, inclusive of monitoring costs. Analogously one can show $\left(\partial l / \partial \varepsilon^{*}\right)_{B_{1}^{*} \text { const }}=(1+r)(1-\theta)\left[\int_{-\bar{\varepsilon}}^{\bar{\varepsilon}} f(\varepsilon) d \varepsilon-\omega\right] /\left(1+\varepsilon^{*}\right)$. As long as the supply of debt is upward sloping this is positive, implying that the higher default risk is also associated with a higher mean return to the lending country.

The condition $\Delta<0$ can be expressed in the form

$$
\frac{\left(\partial c / \partial \varepsilon^{*}\right)_{B_{1}=c o n s t}}{\left((1+r) /\left(1-\theta^{*}\right)\right) \int_{\varepsilon^{*}}^{\tilde{\varepsilon}} f(\varepsilon) d \varepsilon}>\frac{\left(\partial l / \partial \varepsilon^{*}\right)_{B_{1}=c o n s t}}{1+\rho-\theta}
$$

and intuitively asserts that an increase in default risk has a relatively greater impact on the borrowing costs of the emerging economy than it does on the returns to lending of the high income block. The pair of inequalities $\int_{-\bar{\varepsilon}}^{\bar{\varepsilon}} f(\varepsilon) d \varepsilon>\omega, \Delta<0$ impose restrictions on the marginal bailout costs to the borrowing country, $\omega$, which we can express in the form:

$$
\int_{\varepsilon^{*}}^{\bar{\varepsilon}} f(\varepsilon) d \varepsilon>\omega \equiv \frac{\mu f\left(\varepsilon^{*}\right)}{\chi Y^{*}}-\int_{-\bar{\varepsilon}}^{\varepsilon^{*}} \phi\left(1+\eta_{\phi, b}\right) f(\varepsilon) d \varepsilon>\int_{\varepsilon^{*}}^{\varepsilon} f(\varepsilon) d \varepsilon-\frac{(1+\rho /(1-\theta))}{(1+r) \int_{\varepsilon^{*}}^{\bar{\varepsilon}} f(\varepsilon) d \varepsilon} \Gamma
$$

The inequalities in (20) can be transformed to upper and lower bounds on the monitoring costs $\mu .^{12}$

In addition, we can establish:

\footnotetext{
12The condition $\Delta<0$ may appear to impose unrealistically high restrictions on monitoring costs. Taking $\theta=\theta^{*}=0$, the right hand inequality in (20) implies that the share of monitoring costs to the total value of the claim [debt plus interest] exceeds $(1+\rho) /\left(1+\rho^{*}\right)$. Taking $\rho=0.02, \rho^{*}=0.20$ as representative of real interest rates in advanced and developing economies, the cost ratio must exceed over $80 \%$. This, however, is an artifact of the two period model we are employing. If the model is applied to an infinite horizon and the bailout applies to default on interest costs, the corresponding cost ratio reduces to $\rho / \rho^{*}$, which is of the much more realistic order of $10 \%$. But despite this, our focus on two periods is justified in that it preserves the character of the problem, and has the important advantage of permitting us to analyze the issue in the most transparent way.
} 


$$
\frac{\partial B_{1}}{\partial \theta}=\frac{\chi Y^{*}}{\Delta} \frac{B_{1}}{(1-\theta)}\left[\left(\int_{\varepsilon^{*}}^{\varepsilon} f(\varepsilon) d \varepsilon-\omega\right)(1+r) \int_{\varepsilon^{*}}^{\varepsilon} f(\varepsilon) d \varepsilon-\Gamma\right]
$$

while the effects of the reserve requirements on the international lending rate are:

$$
\begin{aligned}
& \frac{\partial r}{\partial \theta}=\frac{\left(1-\theta^{*}+r\right) f\left(\varepsilon^{*}\right)}{\int_{\varepsilon^{*}}^{\bar{\varepsilon}} f(\varepsilon) d \varepsilon} \frac{d \varepsilon^{*}}{d \theta}<0 \\
& \frac{\partial r}{\partial \theta^{*}}=\frac{\chi Y^{*} r^{*}}{\Delta} \int_{\varepsilon^{*}}^{\varepsilon} f(\varepsilon) d \varepsilon\left\{\left(1+\frac{\rho}{1-\theta}\right)+(1+r)\left[\int_{\varepsilon^{*}}^{\varepsilon} f(\varepsilon) d \varepsilon-\omega\right]\right\}<0
\end{aligned}
$$

Conditions (18), (19), and (21) imply the following. An increase in the reserve requirement imposed by either the lending country or by the borrowing country reduces $\varepsilon^{*}$ and therefore decreases the probability of default and reduces the contractual lending rate. An increase in the reserve requirement imposed by the emerging market leads to an unambiguous decrease in net foreign borrowing. Similarly, an increase in the reserve requirement imposed in the lending country reduces net lending, $B_{1}^{*}$, though gross lending, $B_{1}$, could increase.

The final comparative static exercise of importance concerns the effect of a more generous bailout. We define a more generous bailout scheme as being an increase in the probability of bailing out a given partial default, $b$. A uniform increase in the generosity of the scheme is obtained by modifying the probability of bailout by a shift parameter $\xi$, replacing the initial probability of bailout, $\phi$ with $\xi \phi$, where $d \xi>0 .{ }^{13}$ We can easily show that the effects of a more generous bailout, for given reserve requirements, $\theta, \theta^{*}$ are given by

$$
\begin{aligned}
& \frac{\partial \varepsilon^{*}}{\partial \xi}=-\frac{(1+r) \int_{\varepsilon^{*}}^{\varepsilon} f(\varepsilon) d \varepsilon}{\Delta} \int_{-\bar{\varepsilon}}^{\varepsilon^{*}} b \phi f(\varepsilon) d \varepsilon>0 \\
& \frac{\partial B_{1}^{*}}{\partial \xi}=\frac{-\chi Y^{*}}{\Delta} \Gamma \int_{-\bar{\varepsilon}}^{\varepsilon^{*}} b \phi f(\varepsilon) d \varepsilon>0
\end{aligned}
$$

\footnotetext{
${ }^{13} \mathrm{We}$ assume that, in the relevant range, $\xi \phi<1$. Otherwise, the shift parameter replaces $\phi$ with $\min [1, \xi \phi]$.
} 
Thus a more generous bailout will encourage more borrowing and raise the probability of default, doing so by an amount that is proportional to the bailout itself.

\section{Welfare Effects and Optimal Reserve Policy}

We turn now to the consequences of alternative policies on the welfare of the representative agents in the two country blocks. We shall assess the welfare effects of the exogenous policy changes (i.e. changes in $\theta, \theta^{*}$, and $\xi$ ) analyzed in Section 3, as well as optimal policy and the determination of the optimal reserve requirement from the perspective of the various parties. We first analyze the effects of a reserve requirement imposed on the lending nation and then study the impact of a reserve requirement imposed on the borrower. In analyzing optimal policy, we assume a non-cooperative environment, in which each regulator designs the optimal regulation from his perspective, taking the other's regulation as given. This is eventually contrasted with the global optimal policy derived in Section 5 below.

We assume the presence of lump sum taxes, financing the net cost of the bailout. The expected net bailout cost to the treasury of the high income country is $\int_{-\varepsilon}^{\varepsilon^{*}} b \phi f(\varepsilon) d \varepsilon-\rho \theta B_{1}$. The first term is the expected bailout, the second term adjusts the cost by the government revenue from the risk free loan. The expected utility of the high-income block, adjusted to reflect the lump sum taxes, is ${ }^{14}$

\footnotetext{
${ }^{14}$ In evaluating the expected utility of the representative agent, we consolidate the budget constraints of the private sector with that of the public sector. For simplicity of exposition, we assume that all taxes and transfers are lump sum, and that the public sector demand for public goods is zero. With these assumption, the ultimate first-period consumption is the GNP minus external lending, $Y_{1}-(1-\theta) B_{1}$. Similarly, the consolidated second-period consumption is the second-period GNP plus the expected repayment on the external debt, net of the enforcement cost:

$Y_{1}+(1+r) B_{1}(1-\theta) \int_{\varepsilon^{*}}^{\varepsilon} f(\varepsilon) d \varepsilon+\int_{-\varepsilon}^{\varepsilon^{*}}\left\{\chi Y^{*}(1+\varepsilon)-\mu\right\} f(\varepsilon) d \varepsilon$. Using (10), the second-period consumption can be rewritten as $Y_{2}+(1+\rho) B_{1}-\theta B_{1}-\int_{-\varepsilon}^{\varepsilon^{*}} b \phi f(\varepsilon) d \varepsilon$. hence, the expected utility is

$: V=Y_{1}-(1-\theta) B_{1}+\frac{1}{1+\rho}\left[Y_{2}+(1+\rho) B_{1}-\theta B_{1}-\int_{-\varepsilon}^{\varepsilon^{*}} b \phi f(\varepsilon) d \varepsilon\right]$, which is equivalent to (23).
} 


$$
\begin{gathered}
V\left(\theta, \theta^{*}, \xi\right) \equiv Y_{1}-B_{1}+\frac{1}{1+\rho}\left[Y_{2}+(1+\rho) B_{1}-\left\{\int_{-\bar{\varepsilon}}^{\varepsilon^{*}} b \phi f(\varepsilon) d \varepsilon-\rho \theta B_{1}\right\}\right] \\
=Y_{1}+\frac{1}{1+\rho}\left[Y_{2}-\left\{\int_{-\varepsilon}^{\varepsilon^{*}} b \phi f(\varepsilon) d \varepsilon-\rho \theta B_{1}\right\}\right]
\end{gathered}
$$

From (23) it is clear that the impact of a more generous bailout $(d \xi>0)$ or of an increase in a reserve requirement imposed by either the lending country $(\theta)$ or borrowing country $\left(\theta^{*}\right)$ on the welfare of the high-income block depends upon its impact on the expected bailout cost to the treasury $\int_{-\varepsilon}^{\varepsilon^{*}} b \phi f(\varepsilon) d \varepsilon-\rho \theta B_{1}$.

Turning to emerging market, we have shown in Section 3 above that the expected repayment of the emerging market on external debt of $B_{1}^{*}$ is $\{1+\rho /(1-\theta)\} B_{1}^{*}+\int_{-\bar{\varepsilon}}^{\varepsilon^{*}}\{\mu-b \phi\} f(\varepsilon) d \varepsilon$ (see the discussion preceding (14)). In evaluating the expected utility of the representative agent in the emerging economy, we consolidate the budget constraints of the private sector with that of the public sector. For simplicity of exposition, we assume that all taxes and transfers are lump sum, and that the public sector demand for real goods is zero. With these assumptions, the ultimate first-period consumption is the GNP plus the borrowing. Similarly, the consolidated second-period consumption is the second period GNP minus the repayment on the external debt. The expected utility of the emerging market block is

$$
\begin{gathered}
V^{*}\left(\theta, \theta^{*}, \xi\right) \equiv Y_{1}^{*}+B_{1}^{*}+\frac{1}{1+\rho^{*}}\left[Y_{2}^{*}-\left\{\left[1+\frac{\rho}{1-\theta}\right]_{1}^{*}+\int_{-\bar{\varepsilon}}^{\varepsilon^{*}}\{\mu-b \phi\} f(\varepsilon) d \varepsilon\right\}\right] \\
=Y_{1}^{*}+\frac{Y_{2}^{*}}{1+\rho^{*}}+\frac{1}{1+\rho^{*}}\left\{\left[\rho^{*}-\frac{\rho}{1-\theta}\right] B_{1}^{*}-\int_{-\varepsilon}^{\varepsilon^{*}}\{\mu-b \phi\} f(\varepsilon) d \varepsilon\right\}
\end{gathered}
$$

Our welfare analysis entails focusing our attention on (23) and (24). 


\subsection{Increase in Reserve Requirement in Lending Country}

The effects of an increase in the reserve requirement in the lending country, $\theta$, on the level of welfare of the lending country and the domestic (borrowing) economy are given by:

$$
\begin{aligned}
& \frac{\partial V^{*}}{\partial \theta}=\frac{\partial}{\partial \theta}\left\{\frac{1}{1+\rho^{*}}\left(\left[\rho^{*}-\frac{\rho}{1-\theta}\right]_{1}^{*}-\int_{-\bar{\varepsilon}}^{\varepsilon^{*}}\{\mu-b \phi\} f(\varepsilon) d \varepsilon\right)\right\} \\
& \frac{\partial V}{\partial \theta}=-\frac{1}{1+\rho} \frac{\partial\left\{\int_{-\bar{\varepsilon}}^{\varepsilon^{*}} b \phi f(\varepsilon) d \varepsilon-\rho \theta B_{1}\right\}}{\partial \theta}
\end{aligned}
$$

We turn to the foreign spillover effect first. Differentiating (25a) with respect to $\theta$, the impact on the welfare of the emerging block economies is:

$$
\frac{\partial V^{*}}{\partial \theta}=\frac{1}{1+\rho^{*}}\left[\rho^{*} \frac{\partial B_{1}^{*}}{\partial \theta}-\rho \frac{\partial B_{1}}{\partial \theta}-\chi Y^{*} \omega \frac{\partial \varepsilon^{*}}{\partial \theta}\right]
$$

where $\omega$, defined in $\left(13^{\prime}\right)$, is the marginal impact of a larger bailout on the net expected bailout costs to the borrowing country. Evaluating (26) we find

$$
\frac{\partial V^{*}}{\partial \theta}=\frac{\chi Y \rho B_{1}^{*}}{\Delta(1-\theta)^{2}}\left\{\frac{r^{*} \theta^{*}}{\left(1+r^{*}\right)}-\left(1+\varepsilon^{*}\right) f\left(\varepsilon^{*}\right)\left[1-\frac{\theta^{*}}{1+r}\right]\right\}
$$

Condition (27a) brings out two conflicting factors in determining the effects of the higher reserve requirement imposed by the lending economy on welfare in the borrowing country. On the one hand, by reducing default risk and lowering the world interest rate it raises welfare abroad. But it also reduces net foreign borrowing and thus lowers foreign consumption in the first period, and is welfare reducing. In the important case where there is no reserve requirement in the borrowing nation, $\theta^{*}=0$, the first effect dominates and welfare in the emerging country block is improved unambiguously.

Evaluating (25b), we see that the effect of a higher reserve requirement imposed in the lending country on that country's welfare is 


$$
\frac{\partial V}{\partial \theta}=-\frac{1}{1+\rho}\left[\chi Y^{*} \int_{-\bar{\varepsilon}}^{\varepsilon^{*}} \phi\left(1+\eta_{\phi, b}\right) f(\varepsilon) d \varepsilon \frac{\partial \varepsilon^{*}}{\partial \theta}-\rho\left(B_{1}+\theta \frac{\partial B_{1}}{\partial \theta}\right)\right]
$$

where it will be recalled that $\eta_{\phi, b} \equiv d \ln \phi / d \ln b$ is the elasticity of the bailout probability with respect to the bailout size. The effects described by are ambiguous. While the reduced probability of default has a positive effect on welfare in the high income economy, this is offset by the lower borrowing. Evaluating this expression at $\theta=0$, we can establish that:

$$
\left(\frac{\partial V}{\partial \theta}\right)_{\theta=0}>0
$$

We may summarize these results with

Proposition 1: Starting from an initial situation of no reserve requirements, the introduction of a reserve requirement by the lending country will raise welfare in both economies.

The optimal reserve requirement for the lending country is obtained by setting $\partial V / \partial \theta=0$, thereby minimizing the expected tax payer cost of the bailouts:

$$
\rho\left[B_{1}+\theta \frac{\left.\partial B_{1}\right\rceil}{\partial \theta}\right\rfloor=\chi Y^{*} \frac{\partial \varepsilon^{*}}{\partial \theta} \int_{-\bar{\varepsilon}}^{\varepsilon^{*}} \phi\left(1+\eta_{\phi, b}\right) f(\varepsilon) d \varepsilon
$$

This condition has a simple welfare interpretation -- the left hand side is the marginal benefit associated with raising the extra taxes, paid indirectly by the borrower. The right hand side is the marginal cost associated with the increase in the resource transfers via the bailout. ${ }^{15}$

Substituting from (18a) and (18b) into (25b') the optimal reserve requirement for the lending can be expressed conveniently in the form:

\footnotetext{
${ }^{15} \mathrm{We}$ do have to be careful to ensure that there is a well-defined interior maximum. This is not always the case. For example, if $\theta^{*}=\theta=0$, and the probability distribution $f(\varepsilon)$ is uniform, the condition $\partial V / \partial \theta=0$ yields a minimum. A well-defined interior maximum can be attained for other distributions, such as a truncated normal.
} 


$$
\frac{1}{1+\rho}\left[\int_{\varepsilon^{*}}^{\bar{\varepsilon}} f(\varepsilon) d \varepsilon-\mu \frac{f\left(\varepsilon^{*}\right)}{\chi Y^{*}}\right]=\frac{\Gamma}{(1+r) \int_{\varepsilon^{*}}^{\tilde{\varepsilon}} f(\varepsilon) d \varepsilon}
$$

(recall that $\left.\Gamma \equiv\left[\int_{\varepsilon^{*}}^{\bar{\varepsilon}} f(\varepsilon) d \varepsilon-\left(1+\varepsilon^{*}\right)\left(1-\theta^{*} /(1+r)\right) f\left(\varepsilon^{*}\right)\right]\right)$. Equation (29) determines the optimal threshold break-even probability shock at which the expected tax payer cost of the bailouts is minimized. Given the chosen reserve requirement, $\theta^{*}$, of the borrowing country, this then determines the corresponding optimal reserve requirement in the lending economy. Intuitively, (29) asserts that the expected discounted revenue to the lender from the additional gross loan $\left((1+r) B_{1}^{*}\right)$, less the loss from the expected cost of financial intermediation triggered by marginal gross lending, equals the discounted increase in the mean loan costs abroad $(c) .{ }^{16}$ In the absence of any reserve requirement imposed by the borrowing country $\left(\theta^{*}=0\right)(29)$ simplifies to

$$
\frac{\rho^{*}-\rho}{1+\rho^{*}} \int_{\varepsilon^{*}}^{\tilde{\varepsilon}} f(\varepsilon) d \varepsilon+\frac{\left(1+\varepsilon^{*}\right) f\left(\varepsilon^{*}\right)}{1+\rho^{*}}=\frac{\mu f\left(\varepsilon^{*}\right)}{\chi Y^{*}}
$$

\subsection{Increase in Reserve Requirement in Borrowing Country}

Again we begin with the foreign spillover effect. Differentiating (23) with respect to $\theta^{*}$, yields:

$$
\frac{\partial V}{\partial \theta^{*}}=-\frac{1}{1+\rho}\left[\chi Y^{*} \int_{-\bar{\varepsilon}}^{\varepsilon^{*}} \phi\left(1+\eta_{\phi, b}\right) f(\varepsilon) d \varepsilon \frac{\partial \varepsilon^{*}}{\partial \theta^{*}}-\frac{\rho \theta}{(1-\theta)} \frac{\partial B_{1}^{*}}{\partial \theta^{*}}\right]
$$

We see that in the absence of a reserve requirement in the lending country, $\theta=0$, a higher reserve requirement imposed by the borrowing block has a positive effect on welfare in the lending country. This is because by reducing the probability of default, it reduces the expected bailout cost to the treasury of the high income economy and thus has a positive welfare effect on that economy.

The effect of the higher reserve requirement imposed by the borrowing country on that country's welfare is

16 Note that $\frac{\partial}{\partial\left[(1+r) B_{1}^{*}\right]}\left(\int_{-\varepsilon}^{\varepsilon^{*}} f(\varepsilon) d \varepsilon\right)=\frac{f\left(\varepsilon^{*}\right)}{\chi Y^{*}}$, and that $\left(\partial c / \partial \varepsilon^{*}\right)_{B_{1}^{*} \text { const }}=(1+r) \Gamma /\left(1+\varepsilon^{*}\right)\left(1-\theta^{*}\right)$. 


$$
\frac{\partial V^{*}}{\partial \theta^{*}}=\frac{1}{1+\rho^{*}}\left\{\left[\rho^{*}-\frac{\rho}{1-\theta}\right\rfloor \frac{\partial B_{1}^{*}}{\partial \theta^{*}}-\chi Y^{*} \omega \frac{\partial \varepsilon^{*}}{\partial \theta^{*}}\right\}
$$

and substituting for $\partial \varepsilon^{*} / \partial \theta^{*}, \partial B_{1}^{*} / \partial \theta^{*}$ this may be expressed as

$$
\frac{\partial V^{*}}{\partial \theta^{*}}=\frac{B_{1}^{*} \chi Y^{*}(1+r)}{\left(1+\rho^{*}\right) \Delta} \int_{\varepsilon^{*}}^{\bar{\varepsilon}} f(\varepsilon) d \varepsilon\left\{\left[\rho^{*}-\frac{\rho}{1-\theta}\right] \int_{\varepsilon^{*}}^{\varepsilon} f(\varepsilon) d \varepsilon-\omega\left(1+\rho^{*}\right)\right\}
$$

Using the inequality (20) one can establish that if $\theta=0$ then $\partial V^{*} / \partial \theta^{*}>0$. We may thus state:

Proposition 2: Starting from a situation where there are no reserve requirements, the introduction of a reserve requirement by the borrowing country will raise welfare in both economies.

Recalling the definition of $\omega$, the first order condition characterizing the optimal borrowing reserve requirement can be written as ${ }^{17}$

$$
\int_{-\bar{\varepsilon}}^{\varepsilon^{*}} \phi\left(1+\eta_{\phi, b}\right) f(\varepsilon) d \varepsilon+\frac{\rho^{*}-\frac{\rho}{1-\theta}}{1+\rho^{*}} \int_{\varepsilon^{*}}^{\bar{\varepsilon}} f(\varepsilon) d \varepsilon=\mu \frac{f\left(\varepsilon^{*}\right)}{\chi Y^{*}}
$$

and in general yields an interior solution for the borrowing country's optimal reserve requirement. ${ }^{18}$ This condition has a simple welfare interpretation -- the left hand side is the marginal benefit associated with policy induced increase in borrowing. It increases with the expected bailout plus the difference between the impatience of the emerging market (as measured by the subjective time discount factor $\rho^{*}$ ), and the effective cost of funds borrowed from the high income country, $\rho /(1-\theta)$. The right hand side of (32) is the marginal cost associated with policy induced increase in borrowing, as measured by the increase in the expected cost of financial intermediation triggered by marginal borrowing. It is the

\footnotetext{
${ }^{17}$ One can show that an interior maximum can be attained under more general conditions than for the lending country. Specifically, it may obtain for a uniform distribution.

${ }^{18}$ In the case that $\rho /(1-\theta)>\rho^{*}>\rho, \partial V^{*} / \partial \theta^{*}<0$. Hence, the optimal reserve requirement in the borrowing economy is to set $\theta^{*}=0$.
} 
product of the cost of financial intermediation, $\mu$ times the increase in probability of partial defaults triggered by the borrowing.

Finally, note that in the absence of any bailout, the optimal level of borrowing is determined by

$$
\frac{\rho^{*}-\frac{\rho}{1-\theta}}{1+\rho^{*}} \int_{\varepsilon^{*}}^{\bar{\varepsilon}} f(\varepsilon) d \varepsilon=\mu \frac{f\left(\varepsilon^{*}\right)}{\chi Y^{*}}
$$

In general, the competitive equilibrium is inefficient. It can be shown that in this case, optimal borrowing from the emerging market's perspective calls for taxes on borrowing (or a corresponding optimal requirement on borrowing). ${ }^{19}$ This result is in line with Aizenman (1989), where in a related context is shown the presence of "congestion externality" associated with country risk -- the marginal borrower ignores the impact of his borrowing on the interest rate (and indirectly on the prospect of costly default) affecting all the other borrowers.

\subsection{Welfare Effects of a Bailout}

Consider now a more generous bailout as specified above by an increase in $\xi$. For given reserve requirements $\theta, \theta^{*}$ the impact on the welfare of the lending economy is given by

$$
\frac{\partial V}{\partial \xi}=-\frac{1}{1+\rho}\left[\int_{-\varepsilon}^{\varepsilon^{*}} b \phi f(\varepsilon) d \varepsilon-\frac{\rho \theta}{1-\theta} \frac{\partial B_{1}^{*}}{\partial \xi}\right]
$$

While the direct costs of the higher bailout have an adverse effect on the welfare of the lending country, the higher lending and the associated higher income from reserves are welfare-improving.

The impact on welfare in the borrowing country is:

${ }^{19}$ To verify this, suppose that the borrowing reserve requirement is zero. It can be shown that (16a) implies that $\mu \frac{f\left(\varepsilon^{*}\right)}{\chi Y^{*}}=1-\frac{1+\rho /(1-\theta)}{\left(1+\eta_{1+r, B_{1}^{*}}\right)(1+r)}$, where $1+\eta_{1+r, B_{1}^{*}}=d \ln (1+r) / d \ln B_{1}^{*}$ is the interest rate elasticity along the supply of funds facing the emerging market. Using this equality, (32') can be rewritten as $\int_{\varepsilon^{*}}^{\varepsilon} f(\varepsilon) d \varepsilon=\frac{1+\rho^{*}}{(1+r)(1-a)}$, where $0<a<1$. Recall that in the competitive equilibrium, $\int_{\varepsilon^{*}}^{\varepsilon} f(\varepsilon) d \varepsilon=\frac{1+\rho^{*}}{1+r}$. Comparing the last two conditions, it is evident that for a given interest rate, the probability of default in the competitive equilibrium exceeds the socially optimal probability of default. Equivalently, the competitive equilibrium is associated with overborrowing. 


$$
\frac{\partial V^{*}}{\partial \xi}=\frac{1}{1+\rho^{*}}\left\lceil\int_{-\bar{\varepsilon}}^{\varepsilon^{*}} b \phi f(\varepsilon) d \varepsilon+\left(\rho^{*}-\frac{\rho}{1-\theta}\right) \frac{\partial B_{1}^{*}}{\partial \xi}-\mu f\left(\varepsilon^{*}\right) \frac{\partial \varepsilon^{*}}{\partial \xi}\right\rfloor
$$

From the borrowing country's perspective, the bailout and the higher borrowing and consumption that it permits are welfare-enhancing, while the increased default risk and the associated higher monitoring costs (passed on as higher borrowing costs) have a negative effect.

Setting $\theta=0$ in (33a) and $\theta^{*}=0$ in (33b) we immediately see in the former case, and can establish in the latter, that

Proposition 3a: In the absence of reserve requirements, a more generous bailout reduces the level of welfare in the lending country and enhances welfare in the borrowing country.

Given that the bailout has opposite effects in the two economies, it is of interest to determine the impact on world welfare. Combining (33a) and (33b) we can show

$$
\operatorname{sgn}\left(\frac{\partial\left(V+V^{*}\right)}{\partial \xi}\right)=\operatorname{sgn}\left\{\left(\rho^{*}-\rho\right)\left(\int_{\varepsilon^{*}}^{\varepsilon} f(\varepsilon)-\omega\right)-(1+\rho) \frac{\mu f\left(\varepsilon^{*}\right)}{\chi Y^{*}}\right\}
$$

Overall world welfare is impacted in two ways. First, to the extent that the discount rate in the borrowing country exceeds that in the lending country, the benefits of the higher lending rate to the former exceed the costs to the latter. Second, the higher monitoring costs associated with the increased risk of default are a net welfare loss. We may thus state:

Proposition 3b: The net impact of a more generous bailout on world welfare depends upon whether the net benefits of the higher lending exceed the higher monitoring costs imposed on the borrowing nation.

The implication that a more generous bailout scheme has adverse effects on the lending economy in the absence of reserve requirements is important. It suggests that the introduction of reserve 
requirements by reducing default risk and discouraging borrowing, and thus ameliorating some of the adverse effects of the bailout, may be an integral part of an international bailout scheme. In particular, we assess the effects of a more generous bailout under the assumptions that countries set their respective reserve requirements optimally. We begin first with the lender.

In this case see that the equilibrium conditions (16d), (16f) and the optimality condition (29) jointly determine the equilibrium contractual lending rate, $\hat{r}$, interest rate in the emerging market, $\hat{r}^{*}$ and the threshold break-even productivity shock, $\hat{\varepsilon}^{*}$, in terms of the given reserve requirement of the borrowing country, $\theta^{*}$. The key observation from these relationships is that $\hat{r}, \hat{r}^{*}$, and $\hat{\varepsilon}^{*}$ are all independent of the bailout costs, and are independent of $\xi$. Given $\hat{\varepsilon}^{*}$ and $\hat{r}$, (16b) implies that the reserve is adjusted so as to leave the net borrowing constant, i.e. $\partial\left[(1-\hat{\theta}) \hat{B}_{1}\right] / \partial \xi=0$. The equilibrium relationships (16a) and (16b) then in turn imply:

$$
\begin{aligned}
& \frac{\partial \hat{\theta}}{\partial \xi}=\frac{1-\hat{\theta}}{\rho \hat{B}_{1}} \int_{-\bar{\varepsilon}}^{\varepsilon^{*}} b \phi f(\varepsilon) d \varepsilon \\
& \left(\frac{\partial \hat{B}_{1}}{\partial \xi}\right)_{\theta \text { opt }}=\frac{1}{\rho} \int_{-\bar{\varepsilon}}^{\varepsilon^{*}} b \phi f(\varepsilon) d \varepsilon
\end{aligned}
$$

Equation (35a) asserts that a given increase in the generosity of the bailout will increase the lender's optimal reserve requirement. The resultant increase is higher, the higher is the expected bailout. On the lender's side, there is a trade-off between the optimal reserve requirement and the ability to precommit for a no bailout policy. The greater the credibility of such a policy, the lower is the needed reserve requirement.

The effect of the more generous bailout on the respective welfare in the two countries, after allowing for the optimal adjustment of the reserve requirement is given by:

$$
\left(\frac{\partial V}{\partial \xi}\right)_{\theta \text { opt }}=-\frac{1}{1+\rho}\left[\int_{-\bar{\varepsilon}}^{\varepsilon^{*}} b \phi f(\varepsilon) d \varepsilon-\rho \theta\left(\frac{\partial \hat{B}_{1}}{\partial \xi}\right)_{\theta \mathrm{opt}}-\rho B_{1} \frac{\partial \hat{\theta}}{\partial \xi}\right]
$$




$$
\left(\frac{\partial V^{*}}{\partial \xi}\right)_{\theta \text { opt }}=\frac{1}{1+\rho^{*}}\left[\int_{-\bar{\varepsilon}}^{\varepsilon^{*}} b \phi f(\varepsilon) d \varepsilon+\rho^{*} \frac{\partial(1-\hat{\theta}) \hat{B}_{1}}{\partial \xi}-\rho\left(\frac{\partial \hat{B}_{1}}{\partial \xi}\right)_{\theta \mathrm{opt}}-\mu f\left(\varepsilon^{*}\right)\left(\frac{\partial \hat{\varepsilon}^{*}}{\partial \xi}\right)_{\theta \mathrm{opt}}\right\rceil
$$

Using the fact that $\hat{\varepsilon}^{*}$, and $\hat{B}_{1}(1-\hat{\theta})$ are independent of $\xi$ and substituting (35a) and (35b) we find

$$
\left(\frac{\partial V}{\partial \xi}\right)_{\theta \text { opt }}=\left(\frac{\partial V^{*}}{\partial \xi}\right)_{\theta \text { opt }}=0
$$

Thus we see that the increase in the optimal reserve requirement and the increase in gross lending both raise welfare in the lending country and reduce welfare in the borrowing country, doing so by amounts that exactly offset the direct welfare effects of the more generous bailouts, leaving net welfare in each economy unchanged. We may summarize these important results with

Proposition 4: A more generous bailout increases the lender's optimal reserve requirement. Given this optimal response, the direct welfare effects of the more generous bailout are exactly neutralized, with welfare in both countries, and therefore world welfare, remaining unchanged.

The results differ significantly if the optimal reserve requirement is set by the borrowing country. The procedures are analogous and our results can be summarized. In this case, the value of $\hat{\varepsilon}^{*}$ that corresponds to the optimal reserve requirement set by the borrowing country is determined by the borrower's optimality condition (32). Given $\hat{\varepsilon}^{*}$, (16d) and (16f), then determine $\hat{r}$ and $\hat{r}^{*}$. It is straightforward to show from (32) that more generous bailouts will raise $\hat{\varepsilon}^{*}$ and thereby increase the incidence of defaults, as they will increase the marginal benefits associated with borrowing and stimulate borrowing. ${ }^{20}$ The rationale for this outcome is simple -- the higher borrowing is a mechanism ${ }^{20}$ Equation (32) implies: $\left(\frac{\partial \varepsilon^{*}}{\partial \xi}\right)_{\theta^{*} \text { opt }}=\frac{\left(1+\rho^{*}\right) \int_{-\varepsilon}^{\varepsilon^{*}} \phi\left(1+\eta_{\phi, b}\right) f(\varepsilon) d \varepsilon}{\left[\rho^{*}-(\rho /(1-\theta))\right] f\left(\varepsilon^{*}\right)+\left(1+\rho^{*}\right) \mu f^{\prime}\left(\varepsilon^{*}\right) / \chi Y^{*}}$. Assuming that the probability distribution function $f(\varepsilon)$ is unimodal, and that the probability of default is relatively small so that it lies to the left of the mode, $f^{\prime}\left(\varepsilon^{*}\right)>0$ then $\left(\partial \varepsilon^{*} / \partial \xi\right)_{\theta^{*} \text { opt }}>0$. Taking the differentials of (16d) and (16f) and substituting this expression for $\left(\partial \varepsilon^{*} / \partial \xi\right)_{\theta^{*} \text { opt }}$, we can show 
to induce greater income transfer in the form of bailouts, accomplished via more frequent defaults. It can be verified that the ultimate effect of more generous bailout on the optimal reserve requirement $\theta^{*}$ is ambiguous, as the increase in borrowing increases also the incidence of costly defaults with the payoff of higher income transfer.

The effects on welfare in the two economies are obtained by substituting the expressions for $\left(\partial \hat{\varepsilon}^{*} / \partial \xi\right)_{\theta^{*} \text { opt }}\left(\partial \hat{B}_{1}^{*} / \partial \xi \mid\right)_{\theta^{*} \text { opt }}$ into the derivatives of the respective welfare functions and can be written in the form:

$$
\begin{gathered}
\left(\frac{\partial V}{\partial \xi}\right)_{\theta^{*} \text { opt }}=\frac{-1}{1+\rho}\left\lceil\int_{-\bar{\varepsilon}}^{\varepsilon^{*}} b \phi f(\varepsilon) d \varepsilon-\frac{\rho \theta}{1-\theta}\left(\frac{\partial B_{1}^{*}}{\partial \xi}\right)_{\theta^{*} \mathrm{opt}}\right] \\
\left(\frac{\partial V}{\partial \xi}\right)_{\theta^{*} \mathrm{opt}}=\frac{1}{1+\rho^{*}}\left[\int_{-\bar{\varepsilon}}^{\varepsilon^{*}} b \phi f(\varepsilon) d \varepsilon+\left(\rho^{*}-\frac{\rho}{1-\theta}\right)\left(\frac{\partial B_{1}^{*}}{\partial \xi}\right)_{\theta^{*} \mathrm{opt}}-\mu f\left(\varepsilon^{*}\right)\left(\frac{\partial \varepsilon^{*}}{\partial \xi}\right)_{\theta^{*} \mathrm{opt}}\right\rceil
\end{gathered}
$$

Bailout costs improve welfare in the borrowing country, but reduce it in the lending country. By encouraging borrowing, to the extent that the lending country has reserve requirements, this is welfare improving. Higher lending abroad improves foreign welfare, though the associated higher default risk and higher monitoring costs offset that. Furthermore, summing (38a) and (38b) the qualitative effect of a higher bailout on world welfare, when the borrower sets his reserve requirement optimally satisfies (34). We can summarize our results with:

Proposition 5: More generous bailouts financed by the high income block encourage borrowing and increase the probability of default. The effect of more generous bailouts on the borrower's optimal reserve requirement is ambiguous. In general, the welfare effects in both economies and in the world economy are ambiguous. However, welfare in the lending country is adversely affected in the absence of a reserve requirement in that economy.

$$
\left.\left(\frac{\partial \hat{B}^{*}}{\partial \xi}\right)_{\theta^{*} \text { opt }}=\frac{1}{(1+\rho-\theta)}\left[\chi Y\left(\int_{\varepsilon^{*}}^{\varepsilon} f(\varepsilon) d \varepsilon-\omega\right)\left(\frac{\partial \hat{\varepsilon}^{*}}{\partial \xi}\right)\right)_{\theta^{*} \text { opt }}+\int_{-\varepsilon}^{\varepsilon^{*}} b \phi f(\varepsilon) d \varepsilon\right]>0 .
$$




\section{Global Optimal Reserve Policy}

Suppose now that an international agency is charged with determining the optimal reserve requirements for the two nations that will maximize world welfare, $W \equiv V+V^{*}$. Setting $\partial W / \partial \theta$ $=\partial W / \partial \theta^{*}=0$, yields the common optimality condition: ${ }^{21}$

$$
\frac{\rho^{*}-\rho}{1+\rho^{*}} \int_{\varepsilon^{*}}^{\bar{\varepsilon}} f(\varepsilon) d \varepsilon=\frac{\mu f\left(\varepsilon^{*}\right)}{\chi Y^{*}}
$$

This condition asserts that the reserve requirement should be set such that the expected marginal benefits of transferring the funds from the high income country to the low income country just equal the expected cost of financial intermediation triggered by the borrowing. This defines the globally optimal degree of default risk, $\hat{\varepsilon}_{s}$, say. The fact that the optimal choice of $\theta$ and $\theta^{*}$ both lead to (39) implies that one can be set arbitrarily (zero), while the other must be set to ensure that (39) is met.

The similarity between (39) and (32), the optimal reserve requirement chosen by the borrowing country, acting non-cooperatively, is quite striking. The borrowing economy adjusts the cost of funds by the reserve requirements in the lending country, and in addition takes into account the benefits it receives from the bailout. Assuming (i) $\theta=0$, and (ii) that the probability density function is unimodal, with the risk $\varepsilon^{*}$ being relatively small, so that $f^{\prime}\left(\varepsilon^{*}\right)>0,(32)$ implies that the optimal degree of default risk chosen by the borrower exceeds the globally optimal level of risk, $\hat{\varepsilon}_{s}$.

The comparison with $\left(29^{\prime}\right)$ the optimality condition for the lender acting non-cooperatively in the absence of a borrower's reserve requirement is also interesting. The lender too has an incentive to set the degree of default risk that exceeds the socially optimal level, $\hat{\varepsilon}_{s}$, since by doing so he raises the mean return on his loan.

The optimality condition (39) suggests another interesting parallel between the globally optimal reserve requirement and that obtained when the lender optimizes non-cooperatively. Equation (39) implies that the globally optimal degree of default risk is independent of the generosity of the bailout, $\xi$. It thus follows that the globally optimal reserve requirement and the corresponding degree of gross

${ }^{21}$ We can show that (39) always ensures an interior maximum. 
lending satisfies (35). As a consequence these adjustments neutralize the direct effects of the bailout in accordance with (37) and Proposition 4 applies to the socially optimal reserve requirement. We may summarize these results with

Proposition 6: The impact of a more generous bailout on the equilibrium default risk $\varepsilon^{*}$ is critically dependent upon the existence and determination of reserve requirements. In the absence of reserve requirements, or if they are set optimally by the borrowing nation, acting non-cooperatively, more generous bailout will increase the equilibrium default risk. In contrast, if reserve requirements are set at their global optimum, or they are set by the lending nation, acting non-cooperatively, more generous bailout will leave them unchanged.

\section{Reserve requirements and transparency of exposure}

The rationale for imposing reserve regulations goes well beyond the arguments described thus far. One of the surprises of the crisis in the Far East has been the large information gap between the real exposure of several countries to short term debt and the international bank's perception about this exposure. For example, the Economist commented on 11-Apr-98

"Thailand's secret sales of foreign-exchange reserves in the forward markets made a mockery of its official reserve levels. No one had any idea how enormous South Korea's short-term debt burden was. This opacity worsened the crisis, suggesting global markets would work better if there were more information, of better quality, on a broader range of economic items."

A chief achievement of a comprehensive reserve requirement may be improving the information about the real exposure of the various countries. To understand the desirability of such a system, we turn now to evaluate the operation of the global financial market when there is uncertainty regarding the emerging market's aggregate debt. This will be the case if several lending banks compete without 
sharing the information about their exposure. ${ }^{22}$ To simplify exposition, we consider now the simplest form of exposure uncertainty. Suppose that actual debt is

$$
\begin{array}{ll}
B_{1}(1-\delta) & \text { with probability } 0.5 \\
B_{1}(1+\delta) & \text { with probability } 0.5
\end{array}
$$

where $\delta \geq 0$. Market participants have information only about the distribution and the expected value of the debt, $B_{1}$ The risk neutral market will price the debt such that on average, it breaks even. Hence,

$$
\begin{aligned}
& (1+\rho) B_{1}=0.5\left\{(1+r) B_{1}(1-\delta) \int_{\varepsilon_{l}^{*}}^{\bar{\varepsilon}} f(\varepsilon) d \varepsilon+\int_{-\bar{\varepsilon}}^{\varepsilon_{\varepsilon^{*}}^{*}}\left\{\phi_{l}(1+r) B_{1}(1-\delta)+\left(1-\phi_{l}\right) \chi Y^{*}(1+\varepsilon)-\mu\right\} f(\varepsilon) d \varepsilon\right\} \\
& +0.5\left\{(1+r) B_{1}(1+\delta) \int_{\varepsilon_{h}^{*}}^{\bar{\varepsilon}} f(\varepsilon) d \varepsilon+\int_{-\bar{\varepsilon}}^{\varepsilon_{h}^{*}}\left\{\phi_{h}(1+r) B_{1}(1+\delta)+\left(1-\phi_{h}\right) \chi Y^{*}(1+\varepsilon)-\mu\right\} f(\varepsilon) d \varepsilon\right\}
\end{aligned}
$$

where: $\varepsilon_{l}^{*}=\frac{(1+r) B_{1}(1-\delta)}{\chi Y^{*}}-1 ; \varepsilon_{h}^{*}=\frac{(1+r) B_{1}(1+\delta)}{\chi Y^{*}}-1$

This condition can be conveniently rearranged to yield

$$
(r-\rho) B_{1}=0.5 \int_{-\bar{\varepsilon}}^{\varepsilon_{h}^{*}}\left\{\left(1-\phi_{h}\right) \chi Y^{*}\left(\varepsilon_{h}^{*}-\varepsilon\right)+\mu\right\} f(\varepsilon) d \varepsilon+0.5 \int_{-\bar{\varepsilon}}^{\varepsilon_{l}^{*}}\left\{\left(1-\phi_{l}\right) \chi Y^{*}\left(\varepsilon_{l}^{*}-\varepsilon\right)+\mu\right\} f(\varepsilon) d \varepsilon
$$

Proposition 7: Greater noise regarding the aggregate debt tends to shift the supply of funds facing the emerging market leftwards.

This may be established as follows. Note that the right hand side of (40') is the average value of the expected enforcement cost plus banks revenue losses due to partial default, for different values of the total debt. Under reasonable circumstances, this value is a concave function of the actual debt. ${ }^{23}$ The

\footnotetext{
${ }^{22}$ See Kletzer (1984) for a useful discussion in another context, identifying the implications of asymmetric information on emerging markets borrowings.

${ }^{23}$ Note that$$
\frac{\partial^{2}}{\partial \delta^{2}}\left[\int_{-\bar{\varepsilon}}^{\varepsilon_{h}^{*}}\left\{\left(1-\phi_{h}\right) \chi Y^{*}\left(\varepsilon^{*}-\varepsilon\right)+\mu\right\} f(\varepsilon) d \varepsilon\right]=\frac{\left\{B_{1}(1+r)\right\}^{2}}{\chi Y^{*}}\left[\mu f^{\prime}\left(\varepsilon_{h}^{*}\right)-\int_{-\bar{\varepsilon}}^{\varepsilon_{h}^{*}}\left\{2\left(\phi_{h}\right)^{\prime}+\left(\phi_{h}\right)^{\prime \prime}\left(\varepsilon^{*}-\varepsilon\right)\right\} f(\varepsilon) d \varepsilon\right] \text {. }
$$ 
concavity of this term implies that greater volatility of the actual debt (as is the case if $\delta$ goes up), will reduce the right hand side of (40'), implying a drop in the value of expected debt supported by a given interest rate. Figure 1 provides a vivid illustrating of this argument by plotting a simulation of the dependency of the supply of credit on the exposure uncertainty. The effect of uncertainty regarding the aggregate debt is to shift the supply of credit inwards, reducing the elasticity of the supply of credit facing the borrower. In fact, it may dry up the market, as will be the case if we start with a significant initial debt. In these circumstances, the imposition of reserve requirement, and the public dissemination of the total debt exposure of the emerging market economies will shift the supply of credit outwards, increasing the elasticity of the supply of credit facing the borrower, and may even prevent the drying up of the market.

These informational benefits are quite independent from the actual size of the reserve requirement, as long as it is diligently recorded and disseminated to market participants. Note, however, that the compliance incentives of creditors may differ from those of the debtors, and one may argue that due to time inconsistency considerations it may be preferable to impose such a requirement on the lender side. A side effect of improving the information about the aggregate exposure is to lower the optimal reserve requirement -- the improve information would reduce the interest rate on a given debt level, and would increase the credit supply responsiveness to the interest rate. Both effects would reduce the expected default, and tend to reduce the lender's optimal reserve requirements.

From the nature of the "too big to fail" hypothesis, one expects $\int_{-\bar{\varepsilon}}^{\varepsilon_{h}^{*}}\left\{2\left(\phi_{h}\right)^{\prime}+\left(\phi_{h}\right)^{\prime \prime}\left(\varepsilon^{*}-\varepsilon\right)\right\} f(\varepsilon) d \varepsilon>0$. Hence, as long as the responsiveness of the bailout probability to the default size is large relative to the cost of contract enforcement,

$\frac{\partial^{2}}{\partial \delta^{2}}\left[\int_{-\bar{\varepsilon}}^{\varepsilon_{h}^{*}}\left\{\left(1-\phi_{h}\right) \chi Y^{*}\left(\varepsilon^{*}-\varepsilon\right)+\mu\right\} f(\varepsilon) d \varepsilon\right]<0$. In these circumstances, the term

$\int_{-\varepsilon}^{\varepsilon_{h}^{*}}\left\{\left(1-\phi_{h}\right) \chi Y^{*}\left(\varepsilon^{*}-\varepsilon\right)+\mu\right\} f(\varepsilon) d \varepsilon$ is concave with respect to $\delta$. The concavity of this term implies that greater volatility of the actual debt (as is the case if $\delta$ goes up), will reduce the right hand side of (40), leading to a drop in the value of expected debt supported by a given interest rate. 


\section{Concluding remarks}

Global financial markets have witnessed major instability in the 1990s. As one possible means to overcoming this problem, Chairman Alan Greenspan recently proposed the imposition of reserve requirements on lenders and/or borrowers. The rationale for the reserve requirements is provided by the presence of various externalities. On the lender side, the anticipation of bailouts introduces an externality, where marginal lending impacts adversely the tax payer. On the borrower side, as long as partial defaults are costly, marginal borrowing affects all agents by increasing the probability of costly default that would impact all.

This paper has conducted a rigorous analysis of reserve requirements on international financial loans, analyzing their impact through the externalities on the respective welfare of the borrowing and lending nations in the world economy. Our analysis has suggested that the introduction of reserve requirements by either borrowers or lenders will indeed impose the kind of discipline on the international financial market envisaged by Chairman Greenspan. Borrowing will decline, and so will default risk, reducing the necessity for continuing bailouts.

The introduction of reserve requirements will improve welfare in both the lending and borrowing economies. But the design of the optimal reserve requirement in a decentralized world is a delicate matter and both the optimal lender's reserve requirement and the optimal borrower's requirement have both attractive and unattractive features. The choice of an optimal reserve requirement from a lender's standpoint may or may not yield an interior optimum, depending upon the nature of the probability distribution determining the risk in the borrowing economy. However, if an interior optimum exists, it has the characteristic that the corresponding degree of default risk is independent of the generosity of the bailout, just as is the case for the globally optimal reserve requirements. On the other hand, while the attainment of an interior optimal reserve requirement for the borrower is almost always ensured, it has the undesirable characteristic that more generous bailouts are associated with higher degrees of default risk. The ultimate assessment of the desirability of the reserve requirement scheme rests on the assessment of the credibility of "no bailout" policy. As the record of the nineties suggests, we are far 
away from resolving these time inconsistency difficulties, suggesting that reserve requirement should be considered seriously as a valuable policy option. 


\section{References}

Agénor, P. R. and J. Aizenman, (1998), "Volatility and the Welfare Costs of Financial Market Integration," NBER WP \#6782.

Aizenman, J., (1989), "Country Risk, Incomplete Information and Taxes on International Borrowing," Economic Journal, 99, 147-161.

Bardhan, P.K., (1967), "Optimum Foreign Borrowing," in Essays on the Theory of Optimal Economic Growth, K. Shell, ed., Cambridge MA, MIT Press.

Bernanke, B. and M. Gertler, (1989), "Agency Costs, Net Worth, and Business Fluctuations," American Economic Review, 79, 14-31.

Bhandari, J., N. Haque, and S.J. Turnovsky, (1990). "Growth, External Debt, and Sovereign Risk in a Small Open Economy," IMF Staff Papers, 37, 388-417.

Boyd, J.H. and B.D. Smith, (1994), "How Good are Standard Debt Contracts? Stochastic versus Nonstochastic Monitoring in a Costly State Verification Environment," Journal of Business, 67, $539-561$.

Bulow, J. I. and K. Rogoff, (1989), "A Constant Recontracting Model of Sovereign Debt," Journal of Political Economy, 97, 155-178.

Caballero, R. J. and A. Krishnamurthy, (1998), "Emerging Markets Crises: An Asset Market Perspective," manuscript, MIT.

Diaz-Alejandro, C.F., (1984),"Goodbye Financial Repression, Hello Financial Crash," Journal of Development Economics, 19, 1-24.

Dooley, M., (1997), "A Model of Crises in Emerging Markets," \# NBER WP 6300.

Eaton, J., M. Gersovitz, and J. Stiglitz, (1986), "The Pure Theory of Country Risk," European Economic Review, 30, 481-513.

Helpman, E., (1989), "The Simple Analytics of Debt-Equity Swaps," American Economic Review; 79, 440-51. 
Hughes, J. P. and L. J. Mester, (1993), "A Quality and Risk-adjusted Cost Function for Banks: Evidence on the Too-Big-to-Fail Doctrine," Journal of Productivity Analysis, 4, 293-315.

Kletzer, K., (1984), "Asymmetries of Information and LDC Borrowing with Sovereign Risk," Economic Journal , 94, 287-307.

Krugman, P., (1998), "Start Taking the Prozac," Financial Times, April 9.

McKinnon, R. I., (1982), "The Order of Economic Liberalization: Lessons from Chile and Argentina," Carnegie-Rochester Series on Public Policy, 17: 159-86..

McKinnon, R. I. and H. Pill, (1996), "The Overborrowing Syndrome," in Financial Deregulation and Integration in East Asia, T. Ito and A. O. Krueger, eds. Chicago, University of Chicago Press.

Obstfeld, M. and K. Rogoff, (1996), Foundations of International Macroeconomics, Cambridge MA, MIT Press.

Rodrik, D., (1998), "Who Needs Capital Account Convertibility?" manuscript, The Kennedy School, Harvard University.

Townsend, R.M., (1979), "Optimal Contracts and Competitive Markets with Costly State Verification, Journal of Economic Theory, 21, 265-293. 


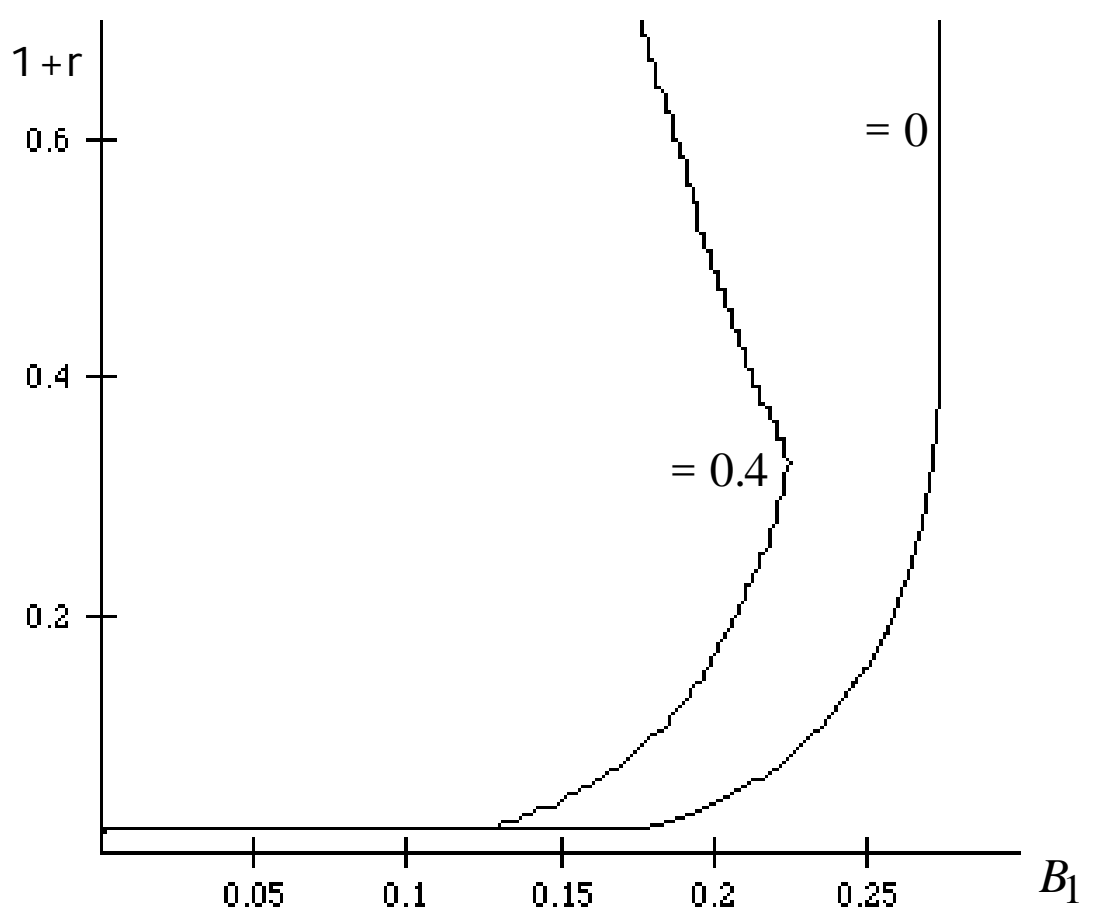

Figure 1

Simulated for the case where $\varepsilon$ follows a uniform distribution, where $\delta=0.4 ; Y^{*}=1 ; \rho=0.02 ; \chi=0.3 ; \mu=0.02 ; \varepsilon=0.4$ 